\title{
QUADRINHOS E FEBRE GEEK RELATO DE UMA IDA À COMIC CON EXPERIENCE
}

\begin{abstract}
Mariana Conde Moraes Arcuri é pós-doutora em Estudos Culturais pelo Programa Avançado de Cultura Contemporânea / UFRJ e doutora em Letras Vernáculas / Literatura Brasileira pela UFRJ. E-mail: mariarcuri@yahoo.com.br

Resumo

Este trabalho busca fornecer uma apreciação sobre uma visita à ComicCon Experience, evento de cultura geek, organizado em São Paulo em 2015. Nas narrativas contemporâneas, os quadrinhos desempenham papel essencial. Este relato passeia pela cultura geek, hoje fortemente presente, por meio de uma abordagem subjetiva dos vários aspectos desse mundo, com uma tentativa de aproximação das bases,

Abstract

This paper aims at providing na observation of a visit to ComicCon Experience, a geek culture event, held in São Paulo in 2015. In contemporary narratives, comics play a major role. This report wanders through geek culture now massively spread, in a subjective approach to the several aspects of this world, with na attempt to approach the bases, consequences, features and imagery of this universe.
\end{abstract} repercussões, características e imaginário desse universo.

Faço aqui um relato sobre minha experiência da ida à ComicCon Experience (CCXP), organizada em São Paulo de 3 a 6 de dezembro de 2015. A percepção que vem à tona neste trabalho, portanto, parte de uma vivência pessoal para expor os pontos testemunhados e sentidos quando de minha visita à feira. Trata-se, assim, de um tratamento afetivo - e não teorizante - dos principais fatores notados nessa estada. Aqui, proponho um passeio pelo evento e pela cultura geek ali fortemente presente, uma abordagem subjetiva, quase intuitiva, dos vários aspectos desse mundo, numa viagem, numa tentativa de aproximação das bases, repercussões, características e imaginário desse universo. Escolhi um desfiar de reflexões, um folhear, numa leitura que não se põe como definitiva, última - pelo contrário, o olhar aqui lançado é apenas um entre tantos possíveis. A visão eleita foi a de uma observadora implicada, prolongando a jornada vivida na CCXP ao narrá-la, participando intimamente, ainda que não como fã, das experiências compartilhadas pelo público ao longo do evento, seguindo as sendas que essas narrativas anunciam.

O ano de 2015 foi o segundo de existência do evento, cuja temática maior é a cultura geek, com subeixos como os quadrinhos, a fantasia, os super-heróis ("encarnação colorida da alma humana", nas palavras de Lourenço Bustani, consultor de tendências de comportamento e integrante da mesa de abertura da Business Summit da CCXP) personagens abordados com frequência já há algum tempo pelo entretenimento. O evento contempla os variados desdobramentos da cultura geek: quadrinhos, literatura, séries de TV e streaming, animações, cinema, brinquedos, games, itens colecionáveis.

Vale lembrar que geek é um termo que designa fãs de jogos eletrônicos, videogames, RPG, tecnologia, quadrinhos, cinema, livros, séries, mangás e animês, formando um grupo que não vê problema em ser considerado "diferente" ou "excêntrico". 
Antes tido como um nome pejorativo, o termo "geek" passou a ser utilizado pelos próprios integrantes da tribo como fonte de orgulho e autoafirmação, distanciando-os de modelos de comportamento encarados como mais habituais.

A designação de geek foi se transformando com o passar do tempo: no século XIX, geek era uma espécie de performer ambulante, um artista de rua, que se apresentava em feiras, circos e festivais, agindo como um louco que comia a cabeça de galinhas ou cobras vivas, num registro do extremo e do bizarro. Nos primeiros momentos da década de 1990, a palavra aplicava-se sempre a um louco por computação que "devorava" bugs (falhas em programas de computador) como sustento - alguém visto como "antissocial" e "monomaníaco". Hoje, o termo serve para nomear um apaixonado por um determinado campo do saber, um conhecedor, um expert em tecnologia, inteligente, culto - e às vezes deslocado.

Por vezes confundido com o nerd, o geek se afasta dele por algumas divergências, com conotações diferentes relativas a cada um. O nerdsobressai por ser alguém pouco sociável, ensimesmado, dedicado à exaustão aos estudos e resultados acadêmicos, com roupas e estilo considerados ultrapassados e pouco atraentes. Enquanto a denominação nerd parece continuar a ter um tom altamente depreciativo, o termo "geek" passou a se revestir de caráter positivo, embora os geeks ainda sejam vistos, quase sempre, como "estranhos" pelos não geeks.

A maré mudou no início dos 1990, quando a tecnologia começou a promover uma revolução no dia a dia das pessoas ao redor do mundo, transformando radicalmente hábitos, padrões culturais e relações sociais. Incorporando uma espécie de poder liberador, a tecnologia alterou a forma como se enxergavam aqueles ligados em eletrônicos, fissurados em jogos, videogames, programação - que passaram a contar com uma aceitação, por outras tribos, mais significativa. Como a vivência cotidiana tornou-se inseparável da tecnologia, com traspassamentos incessantes dos fluxos informativos e culturais, o respeito pelos geeks parece crescer. Não à toa, há agora manifestações de autoafirmação, como festivais, paradas e o Dia do Orgulho Geek.

Assim, na década de 1990, o Jargon File (também conhecido como Hacker's Dictionary), um glossário e manual do jargão da programação computacional, criado pela primeira geração de precursores da internet - ainda na era da Arpanet -, definiu o geek como

alguém que escolheu a concentração em vez da conformidade; que busca habilidades (em particular, habilidades técnicas) e a imaginação, não a adequação social padronizada. Geeks em geral sofrem de neofilia. A maioria dos geeks é hábil com computadores e considera o termo "hacker" prestigioso, mas nem todos são, eles próprios, hackers - e alguns que, de fato, são hackers normalmente acabam se autointitulando geeks, porque veem (de modo bastante adequado) "hacker" como uma classificação que deveria ser conferida a terceiros em vez de usada para se referir a si mesmo.

Uma descrição acurada, embora um pouco longa, enumera gamers, ravers, fãs de ficção científica, punks, programadores, nerds, subgenii, trekkies. Essas são pessoas que não 
foram à festa de formatura da escola, e muitas ficariam ofendidas com a simples ideia de que deveriam ter desejado ir (RAYMOND, 2000, p.458)

Esse domínio do mundo geek coincide com a era dos novos ídolos, novos ideais compartilhados: ao contrário do passado, em que adolescentes incensavam estrelas do rock, atletas, bilionários, figuras tornadas célebres pelo que nelas havia de espetacular, de extraordinário, hoje as inspirações são Bill Gates, Mark Zuckerberg, Larry Page, Sergey Brin, Steve Jobs, sujeitos "estranhos", estudantes que, na garagem de casa e em alojamentos, pensaram novas tecnologias capazes de alterar, de modo intenso e direto, a vida de grande parte da população mundial. Com a mudança no modelo de atribuição de valores, os novos ídolos passaram a ser moldados com base no grau de empatia e identificação - afinal, também eles parecem "pessoas como nós". O que gera a admiração dos geeks por essas figuras é, precisamente, o caráter aparentemente prosaico de suas personalidades, a falta de glamour, de grandiosidade. De novo, temos a vitória do sujeito comum sobre o sensacional. Um dos aspectos mais interessantes nessa cultura mundializada é a vontade de se integrar ao todo, de se inteirar à comunidade: longe das supercelebridades instantâneas que aparecem sem cessar, os geeks se assumem como pessoas "comuns", sem grande afetação, partilhando suas experiências, seu imaginário e suas afinidades em redes sociais e encontros como a ComicCon.

Voltando à CCXP, em primeiro lugar, há que se ressaltar o gigantismo do encontro, que em apenas uma edição - 2014, com público de aproximadamente 100 mil pessoas - se tornou o segundo maior do mundo na área, logo atrás da San Diego ComicCon, e a maior primeira edição de um evento indoor no Brasil. Em 2015, San Diego amealhou um público de 130 mil visitantes; o recorde ocorreu em 2009, com 140 mil presentes. A maior ComicCon do mundo, em tamanho, programação e extensão, San Diego demorou quase 50 anos para se consolidar e chegar a esse posto, em termos de estruturação, pujança, público, capacidade de atração de mídia. Há ainda a Nova York ComicCon, uma experiência relativamente recente (começou em 2006 e em 2015 teve um público recorde de 167 mil pessoas), e em São Paulo a ComicCon Experience, que em dois anos caminha a passos largos para se tornar a maior do mundo, empatando com San Diego, em termos de público, já no ano passado. O alcance do evento mostra-se também pela presença da Netflix, no auge da popularidade do streaming, participando de sua primeira ComicCon, logo no Brasil, na primeira edição da CCXP.

Em 2015, o público de 142 mil visitantes lotou a São Paulo Expo, sobretudo no segundo e terceiro dias de evento (sexta e sábado, 4 e 5 de dezembro), ocupando completamente corredores e espaços disponíveis, a ponto de torná-los, em alguns momentos, quase intransitáveis. Na edição de 2016, conforme informação divulgada pela própria CCXP em suas redes sociais, o evento será 2,5 maior que a edição inicial e $80 \%$ maior que em 2015, passando de $55 \mathrm{mil} \mathrm{m}^{2}$ para $100 \mathrm{mil} \mathrm{m}^{2}$ e ocupando toda a área da São Paulo Expo, que sofreu reforma e modernização a fim de se tornar o maior centro de convenções da América do Sul. 
Se a segunda edição da CCXP atraiu 142 mil pessoas, fazendo do evento a terceira maior feira de cultura pop do planeta, a expectativa é que, com a ampliação da São Paulo Expo, esse número cresça para 180 mil visitantes. Caso as projeções sejam confirmadas, a CCXP pode ultrapassar as edições 2015 da ComicCon de San Diego e de Nova York e se tornar o maior encontro do setor no mundo.

Os ingressos, caros, terão em 2016 os mesmos valores praticados em 2015, com a existência de meia-entrada para os que doarem um livro - iniciativa presente desde a edição original. O passe mais barato para os quatro dias é vendido a 320 reais, na meiaentrada; o ingresso na Business Summit custa mil reais. Para facilitar a compra por parte de um público não exatamente abastado, o pagamento é disponibilizado em parcelamento em até 12 vezes.

O gigantismo salta aos olhos de modo quase instantâneo: desde a escolha do lugarsede, um centro de exposições colossal próximo ao bairro do Jabaquara, nas orlas de São Paulo, passando pela quantidade de gente a transitar - uma multidão incrível -, pela estrutura pensada e erguida para receber o público e os participantes (estandes, lojas, auditórios, locais de alimentação, cinema de 2.500 lugares montado especialmente para o evento, esquema de transporte gratuito para levar o público da estação mais próxima de metrô até o centro de exposições, venda e distribuição de ingressos), até a logística estabelecida, tudo se encaixa nesse caráter mega.

Outra questão que impressiona um visitante de primeira viagem (meu caso) é a potência do tom geek que marca a ComicCon Experience. Muito mais que uma tribo, a comunidade geek vem se fortalecendo enormemente. Pelo robustecimento da tecnologia e das infinitas e ricas trocas tornadas possíveis graças às redes sociais, a fantasia entrou de vez na ordem do dia, incorporando-se ao dia a dia. Na opinião de alguns palestrantes do evento, a magia age como espécie de fonte terapêutica a "colorir" o mundo cotidiano; a fantasia, o lúdico seriam, portanto, veículos de uma felicidade num contexto por eles tido como, por vezes, turbulento.

Pierre Mantovani, fundador do portal Omelete, de entretenimento, e um dos responsáveis pela criação da CCXP, observou de modo pertinente: "Quando nós éramos jovens, há 30, 20 anos, era muito ruim, pejorativo, ser visto como diferente - ser a pessoa que gosta de ler, que gosta de super-heróis. Você era o nerd, o esquisitão, o ponto fora da curva." A pesquisa on-line Geek Power 2015, organizada e conduzida pelo Omelete, teve a participação de 14 mil internautas respondendo aos questionários. Assim também ocorre com outras enquetes na rede, que demonstram o apelo e o viço desse universo. Antes marginal e marginalizada, a cultura geek hoje perpassa o mundo e está em foco, alcançando pessoas de faixas etárias, extrações e experiências diversas, numa permeabilização de vivências tornada possível pelas próprias características do mundo pop - ele mesmo disposto a aproximações variadas. Estigmatizada por muitos, a cultura pop dribla maniqueísmos e, em porções certeiras, funciona como uma espécie de canal amplificador. Numa espiral de conteúdos, a cultura pop renova-se a partir de multiplataformas que se intercomunicam: games, HQs, cinema, séries de TV, músicas. 
De uns tempos para cá, com o vigor da cultura geek que toma o entretenimento (sobretudo quadrinhos e cinema), todos de alguma forma têm acesso a isso, estão inseridos nisso, participando desse mundo. Há 40 anos, havia material produzido e disperso em TV e cinema, numa potência latente; hoje, esse material encontra-se reunido e fortalecido sob o guarda-chuva do entretenimento, contribuindo para a consolidação de um fenômeno cultural. Assim, o que antes era um fator de exclusão, num nicho periférico, agora se torna um elemento constitutivo dessa cultura urbana, circundante, partilhada por todos - geeks e não geeks. A tensão entre ser nicho e ser mainstream persiste, rendendo um debate interessante, com percepções distintas por parte dos diferentes públicos. A fim de se firmar além da cultura de nicho, o geek perde, cada vez mais, o viés nerd e assume um tom mais pop, reforçando seu apelo e suas temáticas.

Bebendo na fonte da San Diego ComicCon, que surgiu como uma feira de venda/compra e troca de revistas em quadrinhos usadas, a CCXP oferece um lugar de destaque para os quadrinhos. Aqui, como na Califórnia, é possível ter contato direto com profissionais dos quadrinhos (coloristas, roteiristas, ilustradores, quadrinistas), numa área dedicada especificamente a eles - a Artists' Alley, origem das Comic Con. Ali cada artista ocupa uma mesa com sua produção, livros, desenhos, originais, e está à disposição do público para trocar ideias, dar autógrafos, tirar fotos, ser entrevistado, conversar. Essa era a motivação inicial de San Diego - ter os quadrinhos como base, garantindo a eles a posição de linguagem original, independente - e a noção permanece na CCXP.

Com 30 mil quadrinistas no Brasil, a Artists' Alley é representativa da classe, um dos setores mais robustos do evento, com mais de 250 artistas presentes - todos recebendo o mesmo espaço e grau de visibilidade -, tietagem intensa, grandes filas, fotos, longos bate-papos. Alguns célebres, como Mike Deodato, Gabriel Bá, Fábio Moon, Rafael Coutinho, Mike McKone, Lobo, outros mais iniciantes - todos ao alcance do público. A interação propiciada pela liberdade de encontro é um dos pontos altos da CCXP, uma de suas matrizes.

Ao longo da pesquisa, ficou clara a presença de dois vieses bastante distintos no universo dos quadrinhos, ambos originados de um mesmo solo: a tira desenhada (bande dessinée), roteirizada seriadamente a partir de uma ilustração, com uma história a ser contada. $\mathrm{Na}$ visão dos próprios quadrinistas, por um lado, há uma inclinação para o entretenimento, com figuras de super-heróis, revistas em quadrinhos, narrativas mais tradicionais, distribuição mais organizada - o desdobramento mais associado à escola americana, com a presença firme de DC e Marvel. Por outro lado, há o desenvolvimento do quadrinho independente, mais aproximado do humor irônico, com forte característica autoral e nível crescente de sofisticação narrativa.

Hoje certos quadrinistas de humor - um humor ácido, mordaz, muito crítico dessa mesma cultura geek que molda boa parte dos quadrinhos de larga escala - não querem nem ouvir falar de histórias em quadrinhos convencionais - aquelas que boa parte do público aprendeu a reconhecer como a totalidade dos quadrinhos (Turma da Mônica, Mickey Mouse e amigos, super-heróis, seres fantásticos). Os quadrinistas mais 
alternativos tematicamente, muitos dedicados a um humor iconoclasta, desvinculam-se da vertente mais fantasiosa dos quadrinhos - André Dahmer, Allan Sieber, Laerte, só para citar alguns poucos e expressivos nomes, donos de uma produção consolidada, prestigiosa e divulgada em veículos de largo alcance, jornais e internet.

Para esses artistas, os quadrinhos comercialmente maciços, de caráter mais fantasioso, frequentemente são vistos como produções infantilizantes; Sieber é enfático ao qualificar essas narrativas de fantasia como "grandes bobagens". Quadrinistas desse grupo são bastante refratários a qualquer tipo de aproximação com os quadrinhos tidos como comerciais, essencialmente pop.

Com a demora no amadurecimento do quadrinho nacional - que existia, mas com dificuldade alcançava o público -, proliferaram os fanzines. O espaço vago foi aos poucos sendo ocupado; ao longo de 15 anos, o mercado foi crescendo, trazendo uma produção maior e mais diversificada, com mais títulos e tiragens menores. Muitos quadrinistas assinalam que, com a consolidação do mercado, a distribuição, hoje, é facilitada: as livrarias têm maior controle, com menos perdas e danos, sobre o material exposto, ao contrário das bancas de jornal. No entanto, habitualmente, somente os quadrinhos mais caros, em formatos mais bem-acabados, seguem para livrarias, por serem vistos como mais adaptados a esse espaço de vendas.

No contexto atual, há, sim, espaço para todos. Os quadrinhos mais autorais, por exemplo, conseguiram na última década reemergir com vigor e cativar um público mais amplo, assegurando uma posição de proa no coração dos leitores e no mercado editorial estabelecido, com lugar específico em editoras e livrarias. Tal florescimento deve-se, em boa medida, à aposta dos atores editoriais no nicho das adaptações de clássicos e narrativas tradicionais para a linguagem dos quadrinhos, numa tentativa de se oferecer a literatura aos jovens de modo atraente. Esse movimento desencadeou-se no bojo dos grandes programas governamentais de compra de livros para o abastecimento de bibliotecas públicas e escolares.

O público a ser seduzido, portanto, era majoritariamente infanto-juvenil, e o

entendimento por parte dos responsáveis pelas escolhas de compras e dos integrantes do mercado editorial foi no sentido de vestir a leitura com roupagem mais atraente ao tornála palatável, acompanhada dos acessórios da imagem e da adaptação. Havia a ideia de que o acesso da criança e do jovem à literatura passava necessariamente pela facilitação, numa adaptação, da leitura. Daí se fez a conexão com os quadrinhos, capazes de adequar a narrativa a uma dinâmica mais visual e acelerada, algo caro e vinculado aos jovens do veloz mundo contemporâneo. Na esteira do boom de compras governamentais, parte da lógica de recolocação dos quadrinhos nas livrarias como estratégia de vendas para o grande público enxergou-os como uma linguagem simplificada - algo que a larga maioria dos quadrinistas rejeita. Para eles, os quadrinhos são esmero, sofisticação, uma linguagem que parte de referências prévias rumo a um conteúdo crítico que espelha situações e vivências cotidianas. 
Em um evento primordialmente consagrado à cultura geek, ao entretenimento, há espaço reservado para criadores mais artesanais, como na já mencionada Artists' Alley. As propostas desses artistas, inovadoras e heterodoxas, vão ao encontro da visão dos quadrinhos como linguagem libertária, independente. A criação do roteiro, das ilustrações, da coloração - da narrativa, enfim - segue normas próprias, não derivações. Foi instigante perceber a coexistência de mundos distintos num mesmo local.

Outro ponto a ser destacado concerne aos visitantes: alternativos, com muitos góticos, milhares de camisetas de seriados ou personagens, dizeres nerds, que em nada se vinculam a uma noção mais "bacana e descolada" de público. Ali não havia juventude dourada - aquela que muitas vezes é apresentada como sinônimo de felicidade, cool, realização, sucesso. A partir da porta de entrada da CCXP o que mais se via eram figuras no mínimo sui generis. Ali havia os renegados, os desajustados, muitas, muitas meninas e mulheres de desbotados cabelos azuis, rosa, lilases, gordinhos com camisas do Superman, de Game of Thrones e Harry Potter, metaleiros, crianças e cadeirantes, adultos acompanhando os milhares de adolescentes, muitos jovens vestidos de preto, homens barbudos com cabeleiras revoltas e vários anéis nos dedos, uma infinidade de bonés multicoloridos, grupos de amigas, sotaques variados, inúmeros fumantes, muitos piercings e enormes tatuagens oldschool, roupas largadonas, tênis velhos, mochilas surradas - todos aparentando se sentir muito felizes de estar lá. Uma quase ode a uma certa década de 90, mais aproximada do grunge, num veio underground que ainda perdura como importante ponto compartilhado da cultura geek.

Temos, assim, um rapaz que, no ônibus saindo do evento rumo à estação de metrô, saca, de dentro de uma sacola Saraiva - creio que adquirida no estande da livraria presente na feira -, um exemplar da Ilíada e começa a folheá-lo. Temos, na entrada do primeiro dia, na fila dentro do pavilhão, meninas que puxam o coro de "Let it go", de Frozen, prontamente atendidas por boa parte da audiência; temos, na espera para embarcar no ônibus em direção à feira, o espanto de duas mulheres que comentam, ao se deparar com um público tão peculiar, "Aquelas coisas de japonês que a gente vê na televisão"; temos uma espécie de Paquita gótica e uma Hello Kitty num estilo "gostosona" atraindo olhares. Uma audiência variada, em suma.

O que se celebra em São Paulo é o fora do padrão: o rejeitado, o zombado, o perdedor, ofreak que se senta isolado dos outros na turma, com quem ninguém quer andar, nunca chamado para festas, não popular. Visualmente, o público passa longe dos padrões estéticos "de revista": sem hype, sem afetação de estilo fashion, sem fumaças de beleza. Os pseudounderground tampouco são bem-vindos: sem posers, sem emos. $\mathrm{O}$ tom dominante é o de um orgulho imenso de se estar ali e ser precisamente daquele jeito; o que antes era um menos vira um pró. Uma quase vingança saboreada com muito prazer: a vendeta de um gosto por vezes taxado de duvidoso, a derrota do senso de ridículo, do comedido, razoável, do refinamento, de pretensões de erudição. Uma derrota clamorosa. "Somos geeks, desajustados, não somos populares, não somos bonitos, não somos 
malhados, não somos ricos, não somos cool. Lutamos para estar aqui. Somos esse triunfo, a vitória da 'festa estranha com gente esquisita' - e gostamos de ser assim."

E assim há a chegada a uma outra questão, crucial para se tentar compreender a pujança e da cultura geek consolidada nos últimos anos - robustez que se dá também pelo dinheiro que esse mundo movimenta. Sem dúvida o sucesso da CCXP se deve ainda ao volume financeiro que ali circula. O dinheiro corria, fosse no setor de alimentação, descomunal e movimentado, fosse nas inúmeras lojas e estandes espalhados pelo evento - grande parte dos estandes e expositores está vendendo alguma coisa; alguns dedicam $100 \%$ de seu espaço às vendas, como a loja do filme Star Wars, surfando no buzz do lançamento do novo episódio da série, com filas intermináveis aumentando a cada dia de evento. Muitos parecem apostar suas fichas nas vendas, orientadas para os mais variados tipos de bolso e faixa etária, com destaque para a fatia que vai dos 15 aos 29 anos, o principal alvo.

Quase tudo se pode comprar: roupas (camisetas, fantasias), máscaras, bonecos, brinquedos, sapatos, quadrinhos, livros, objetos de decoração, bugigangas relacionadas ao mundo dos quadrinhos, dos super-heróis e outros personagens queridos, uma infinidade de acessórios (canecas, mochilas, estojos, maquiagem, baralhos, almofadas, xícaras etc.), itens colecionáveis. Estes, por exemplo, merecem destaque especial, pelos preços alcançados, em média bastante elevados. Afinal, um boneco não é apenas um boneco, mas um item feito de modo quase artesanal em quantidades super-reduzidas um objeto de desejo, portanto.

Apesar dos altos preços cobrados (800 reais por uma espada jedi Star Wars, 4.500 reais por um busto do Coringa, arquirrival do Batman), muitos lotam os estandes de colecionáveis. Isso em meio a um público que não dá mostras de ser particularmente abonado - na chegada ao primeiro dia do evento, na imensa fila para embarcar em um dos ônibus que transportavam, gratuitamente, os visitantes da estação mais próxima de metrô (Jabaquara) até o centro de exposições, pouquíssimos aceitavam abandonar a longa espera e pagar 5 reais, cada um, para dividir um táxi rumo à São Paulo Expo. Ou comprar prosaicos hambúrgueres Bob's a 18 reais na praça de alimentação.

O dinheiro é suado e valorizado. Talvez por isso, os geeks repudiam abertamente a pirataria. Fazem questão do original, embora mais caro, porque o original guarda um valor intrínseco de autenticidade: o enorme apelo está menos na marca, na grife - até mesmo na raridade -, do que na autenticidade daquele objeto. Uma autenticidade pouco replicável, radical, quase como a de um tesouro. O colecionismo na cultura pop alimentase de uma nostalgia - pessoal ou histórica. O consumo, aqui, é completamente especular - o indivíduo enxerga o eu no que coleciona e compra.

O comportamento do fã é, por definição, apaixonado; ele é, essencialmente, alguém que adora - um personagem, uma série, um filme, uma banda. Assim, a atitude do fã lembra, em alguns aspectos, aquela do consumidor, que contempla, admirado, o item almejado. Por isso, o mercado geek reserva um alto poder de consumo, ainda longe de seu limite de esgotamento. Como frisou Marcos Avó, consultor na área de estudos de 
mercado e membro da mesa de abertura da Business Summit, a CCXP é, sobretudo, um evento para o fã, daí a presença marcante do que chama de "lovebrands", marcas pop atraentes para o público - no caso geek, Omelete (portal de entretenimento), PiziiToys (brinquedos e colecionáveis), Chiaroscuro Studios (quadrinhos e arte).

$\mathrm{Na}$ ComicCon, percebemos que bastante é pensado para favorecer o consumo, para contemplar a vontade de ter, de comprar, instigando o desejo por um determinado objeto, um personagem, uma vinculação a uma história. E isso move as paixões do público.

O alcance da força do entretenimento - um gigantesco setor de bilhões de dólares e milhares de pessoas envolvidas - ajuda a explicar o lugar de proa ocupado pela cultura geek no mundo de hoje. Minha aproximação ao universo geek é relativamente recente, derivada de um aprofundamento no universo dos quadrinhos a partir de 2010, ano em que fiz minha primeira pesquisa na área a fim de tentar esclarecer as ligações entre essa linguagem e a literatura infanto-juvenil em meio a um cenário de ressurgimento dos quadrinhos graças à presença em editoras, livrarias, feiras e compras governamentais em suma, na vitrine cultural brasileira.

Antes, meu contato com a cultura pop de caráter marcadamente geek era ocasional, dado por algumas idas ao cinema e pela leitura de certos quadrinhos. Nunca fui uma conhecedora ou consumidora ávida - uma superfã, por assim dizer. Em 2010, tive meu primeiro contato mais íntimo com o setor, e com base nele comecei a desdobrar minha pesquisa, até atingir o momento atual, em que busquei apreender o sentido da ressonância da cultura geek no mundo contemporâneo, e o lugar da fantasia nesse contexto, o porquê de sua preponderância nas narrativas atuais. Imaginava encontrar a vertente da fantasia, estreitamente vinculada à capacidade de paixão do público, e também a do dinheiro.

Em São Paulo participei também de um evento paralelo à ComicCon Experience, a Business Summit, com duração de três dias, uma espécie de painel consagrado unicamente aos negócios. Lá havia debatedores representando variadas divisões do entretenimento: produtores de cinema, produtores de séries, editores, diretores de marketing e produto, diretores de criação, publicitários, produtores executivos de sites de entretenimento como o Omelete (realizador da ComicCon Experience), pesquisadores de tendências, comportamentos e nichos de mercado, consultores, youtubers, quadrinistas, representantes de franquias/licenciamentos.

Nas mesas de business, muito bem organizadas, mediadas e executadas, o foco e a pertinência pareceram muito maiores que nos painéis realizados fora da Summit, com debates mais vinculados ao fazer artístico, centrados no conteúdo essencial do material elaborado. As mesas extra-Business Summit por vezes não atingiam seu propósito e o tema escolhido, perdendo-se em histórias pessoais em detrimento de análises mais profundas do panorama do entretenimento.

A presença de convidados de fora do Brasil tornou possível a troca de alguns insights instigantes. Os executivos estrangeiros sublinhavam, sem cessar, seu assombro com o enorme movimento testemunhado, numa feira que estava apenas em sua segunda 
edição, em época de perspectivas econômicas adversas. O vice-presidente sênior e editor executivo da DC Comics, Dan Didio - um gigante bonachão mascando chiclete, com camiseta de super-herói e boné -, abriu sua apresentação mostrando-se um fissurado pelo conteúdo que ajuda a desenvolver e distribuir: um geek hardcore. Os executivos brasileiros, por sua vez, frisavam mais aspectos econômicos desse universo, distanciandose mais da posição de fãs.

Didio trouxe vários pontos interessantes para sua fala na Business Summit. Começou por esboçar uma trajetória dos quadrinhos, em que realçou a conexão entre seu fortalecimento e o período histórico vivido na época - a Grande Depressão. Na esteira do Crash, floresceram os personagens clássicos dos quadrinhos: os super-heróis, criados especialmente para aquela conjuntura. Na visão de Didio, a fim de manter o apelo dessas figuras, é preciso adaptá-las para o público de hoje, "revivendo o material criativo".

Capturando a sensibilidade de um tempo-espaço particular, os quadrinhos resistem à obsolescência, mesmo com o quase desaparecimento, no cenário americano, das bancas de jornal. Indo contra a tendência de encolhimento do mercado de jornais e periódicos impressos, os quadrinhos encontram novo fôlego no mundo digital, com divulgação costumeiramente gratuita na internet e nas redes sociais. Talvez pela ubiquidade da tecnologia encontrada no cotidiano, as HQs experimentam seu momento de maior popularidade e crescimento, assinalando o caráter singular do mundo em que vivemos.

Outros fatores que ajudam a explicar o viço desse cenário são a emergência das mulheres nas duas pontas desse universo e o boom dos mash-ups. Há cerca de 15 anos, um mercado antes predominantemente masculino viu o crescimento vigoroso e constante do interesse das mulheres. Antes excluídas dessa cena, elas passaram a nela se integrar com intensidade: agora, a proporção de homens e mulheres leitores de quadrinhos é praticamente a mesma. Do lado executivo, especialmente nos últimos 5 anos, também houve uma mudança radical - antes apenas leitoras, as mulheres são, hoje, produtoras, criadoras, participantes.

Num momento de forte reivindicação pela igualdade racial e de gênero, a perspicácia do entretenimento para captar as especificidades de um determinado panorama e adaptar-se a elas pode ser notada em tentativas como o longa-metragem animado "A Princesa e o Sapo" e a série de desenhos "Dra. Brinquedos", ambos da gigante Disney, ambos com protagonistas negras, fortes e resolutas.

Os mash-ups, por sua vez, criaram-se pela combinação de elementos oriundos de duas ou mais fontes, culminando em música, vídeo, filme, livro, narrativa. Os romances mash-up, por exemplo, recriam clássicos da literatura,inserindo-lhes elementos fantásticos e/ou de terror, com um resultado narrativo peculiar. Boa parcela do conteúdo original subsiste, com acréscimos, por autores contemporâneos, de plot twists e personagens, como vampiros, lobisomens e zumbis - exemplos de sucesso incluem "Orgulho e Preconceito e Zumbis" e "Abraham Lincoln: Caçador de Vampiros".

Muitos dos presentes à Business Summit sabem que o fã é, antes de mais nada, um apaixonado, sabem que lidam com uma assimilação muito íntima daquelas narrativas 
- uma mistura difusa de desejos e fantasias. Não à toa, uma expressão ouvida de modo recorrente na Summit foi "evangelizar o público", no sentido de fidelizá-lo àqueles frutos do entretenimento. A alusão religiosa não parece ser por acaso; no reino do sagrado, a intensidade de emoções é ponto fulcral. Os participantes da Summit sabem, em suma, que tratam de personagens e histórias que roçam facetas humanas muito primitivas, originárias - e prezam esse conhecimento. Como afirmou Dan Didio: "Cada história relaciona-se a um arquétipo."

Os responsáveis pelo marketing e licenciamento de produtos da Warner Movies deram um exemplo que considerei sugestivo: um pequeno produtor agrícola fez uma parceria com detentores de direitos de marca e passou a vender suas maçãs em embalagens unitárias com a estampa do Batman. A criança passava a querer a maçã do Batman - não a maçã em si. Há como que um jogo de se transformar o item mais natural, mais cru, em um produto, um resultado, numa alteração do valor simbólico dada pela presença de certo personagem. O produto licenciado não é mais uma fralda, uma cadeira, uma caneca, em indefinições reiteradas - é, sim, a caneca da Mônica, a fralda do Pernalonga, a cadeira do Super-Homem. Artigo definido - a marca determina o valor. Filmes, quadrinhos, brinquedos, séries, comerciais, licenciamento de produtos, todos os produtos participam de uma engrenagem que movimenta muito dinheiro - que, por sua vez, será reinvestido no entretenimento.

Nesse mercado, visto como em expansão pelos atores envolvidos, há uma constante preocupação com a potencialidade econômica. Percebi que tal sentimento não se dava à toa: na CCXP, independentemente da extração social dos ali presentes, havia um desejo por comprar. Como o potencial de gastos é visível, o veio continua aberto, um terreno a ser explorado. O realce do econômico liga-se a outro motor que molda o evento: a febre do fã, do apaixonado. Nesse nicho da cultura pop, tratamos primordialmente de figuras ligadas a modelos partilhados e construídos a partir de camadas de ancestralidade, reinventados e reatualizados numa construção de um imaginário rico e plural, indissociavelmente ligado às questões contemporâneas do sucesso, fama, justiça, igualdade.

Sobretudo ao lidar com a figura do herói, de trajetória narrativa peculiar, senti a intensa identificação por parte dos leitores/espectadores, numa adesão praticamente imediata. A jornada do herói implica busca e enfrentamento de desafios, à maneira da trajetória do homem comum, espelhando-a - como uma espécie de Batman, que sofre medos e traumas e os combate, o homem prossegue. Partindo do mito antigo do herói, o cinema reatualizou essa figura nos últimos dez anos, como fez Christopher Nolan ao eleger o Cavaleiro das Trevas para dissertar sobre as profundezas da alma humana em uma leitura única, pessoal. Dono de grandezas e defeitos - ambos em escala maximizada -, o herói irrompe como o humano potencializado, ser errante que triunfa e cambaleia à procura de si.

Entendido como paroxismo, ou mesmo como extrapolação, do homem, o herói agrega mortalidade e deidade, limite e potência, aplicação e vontade, finitude e 
espraiamento. Ele é, em suma, a representação do humano - e nesse ponto reside a chave para a associação instantânea feita pelo espectador/leitor.

Num mundo em que valores se remodelam, originam-se incertezas; uma época em que, sintomaticamente, se verificam múltiplas ressignificações. Por isso, o ponto de contato entre herói e fã acarreta uma colagem muito forte por parte do último, que incorpora e se imbui da figura do herói. Em outras palavras, ocorre uma reconstrução, uma reinterpretação da própria natureza, num reencontro das potencialidades do ser humano. O herói veicula códigos morais formativos e ajuda a manifestar, com seu simbolismo, questões intensas experimentadas pelo homem. Um dos aspectos mais interessantes nesse renovado imaginário trazido à tona pela cultura geek é o reforço do primordial como base fundamental para o extraordinário; o alter ego é tão heroico quanto o ser superdotado que nele se desdobra. Num contexto em que as trocas culturais e informativas multiplicam-se pelas redes, o substrato compartilhado - o humano - tornase ainda mais valorizado pela intensa capacidade de identificação a partir desse denominador comum. A vinculação aos super-heróis ocorre não pelo que estes trazem de extraordinário, mas pelo que neles existe de original, de primário.

Partindo daí, podemos começar a entender o fenômeno que é a produção e a absorção de heróis e seres fantásticos popularizados na cultura pop contemporânea. $\mathrm{O}$ vigor da fantasia, percebida em diversas narrativas atuais (as séries Harry Potter, $O$

Senhor dos Anéis, O Hobbit, Crepúsculo, Percy Jackson e X-Men, os seriados televisivos True Blood e Game of Thrones, entre outros), remete a uma realocação da realidade. Aí se encontra a questão dos superpoderes - o homem comum que se torna super-homem e entra em contato com o que escapa à previsibilidade, à racionalidade, à ponderação. A raiz é o obscuro do ser humano, o insondável, recôndito ou escondido, numa ebulição de sentimentos que, embora primordiais, vêm à tona esporadicamente. Uma espécie de Fênix Negra, para ficarmos num exemplo bastante adequado, X-Men, fruto do universo de que tratamos aqui.

A força dessas narrativas pode sugerir que o padrão atual - cientificizado, controlador do tempo, da natureza - deixa entrever fissuras no discurso racionalizante, ao excluir o fortuito, o visceral. As narrativas de fantasia, por conseguinte, atuam como pontas de lança das superstições, num jogo entremeado de elementos oníricos, mágicos, por vezes sombrios - o "dark side of the moon". Não deixa de ser interessante perceber que a cultura pop - muitas vezes considerada inútil e frívola - é uma das que mais apresenta questões concernentes a simbolismos, significados.

A fantasia gera uma associação veloz e duradoura com seus espectadores/leitores porque, através dela, se excede o premeditado. Tal articulação acontece de modo quase instantâneo, o que provoca um reconhecimento e uma adesão. $\mathrm{Na}$ medida em que se robustece esse vínculo, marca-se aquele sujeito - e daí vem à tona a figura do fã, fan, fanatic, movido por adoração, devoção mesmo. Ele, que se apega àquelas figuras, que se aferra àquelas personagens, que se torna um quase duplo daqueles seres. 
Encontramos, logo, a questão: quem é o fã e quem é o personagem? O fã já se enxerga como personagem. $\mathrm{O}$ foco de quem desenvolve conteúdo para o público geek é o fanático hardcore; os próprios produtores desse tipo de entretenimento se reconhecem como fãs, como geeks, o que contribui para firmar uma coletividade coesa e articulada. $\mathrm{O}$ fã segue para o encontro com os personagens, os produtos, os colecionáveis, assumindo completamente sua condição inequívoca de fã. Entre seus semelhantes, ele é, simultaneamente, apenas mais um e o centro das atenções.

O fã participa de acontecimentos como a CCXP para estar "em família", cercado por aqueles que ele reconhece como seus pares. Assim, chega ao evento preparado para aquele tipo de experiência, de diálogo com seus próximos - com gradações que vão do ultrafã aos simpatizantes. Compartilhando um substrato imaginário globalizado, em que um fã local se sente completamente confortável para debater, com alguém do outro lado do planeta, as reviravoltas narrativas de Game of Thrones ou da saga fílmica X-Men, os geeks formam, assim, uma comunidade geograficamente espalhada e tematicamente consolidada.

Com base nesse aspecto, ficamos mais perto de entender a pujança do entretenimento, inteligente em adotar a vinculação das figuras fantásticas à própria face dark da natureza humana. Abalada pelo factual, a crença mística, muitas vezes tratada de modo pejorativo, parece ressurgir sob as roupagens da superstição, ressoando em narrativas que espelham o íntimo de seus fãs. Como já mencionado, os produtores e executivos mostraram-se sagazes ao perceber o potencial das narrativas fantásticas, de uma parte da sociedade encantada pela fantasia, por encontros com uma natureza mais sombria - seu monstro interior, seu lobo atrás da porta. Ao apostar, acertadamente, nessa relação, o entretenimento floresce e funda uma rede de troca de experiências e vivências.

Outro ponto interessante a se abordar é a existência dos cosplayers (costume players), pessoas que se vestem e se ornamentam como seus personagens favoritos e participam de eventos como a CCXP, a Jedicon, as ComicCon mundo afora incorporando essas figuras. O termo "incorporar", aliás é bastante apropriado: à semelhança das religiões de matriz africana, em que o cavalo recebe no corpo uma entidade, servindo-lhe como veículo de manifestação, o cosplayer incorpora o personagem, abandonando seu eu primário. Para os cosplayers, trata-se não só de uma questão de roupas e adereços, mas de atitude e autorreconhecimento. Eu nunca havia estado num evento que contasse com cosplayers e me assombrei - na CCXP, havia jedis, siths, com espadas e chapéus, vários Mario Bros, e muitos outros.

Há anos, quando, pela primeira vez, ouvi falar da existência da prática, pensei que cosplays eram como fantasias no Carnaval - descobri que são algo à parte. Teríamos de considerar que as fantasias no Carnaval são igualmente um passaporte para a "magia" isto é, a fantasia é uma roupa, mas é também um faz de conta em que se entra, uma outra realidade que se experimenta, que se encarna. Coloca-se um traje, uma outra identidade, sobre si mesmo e, na medida em que se assimila aquela persona, torna-se aquela persona, em possibilidades de outros eus. Acredito que, no Carnaval, a incorporação do 
personagem já esteja um pouco dissolvida, já não tão gritante. A performance não é tão generalizada. Atualmente, o Carnaval parece compreender a ideia de nos vestirmos de forma incomum, como não faríamos no restante do ano, saindo dos trajes cotidianos. Tal atitude contempla a liberdade e uma rebeldia, não necessariamente uma performance ou uma necessidade de se encontrar em outro alguém. No cosplay, diferentemente, existe uma imbricação completa entre pessoa e personagem.

Dito isso, duas coisas chamam fortemente a atenção dentro do universo dos cosplayers: a primeira é a quantidade expressiva de participantes; e, em segundo lugar, há uma total falta de constrangimento em se fazer cosplay. O ambiente civilizado e previsível, do qual costumeiramente fazemos parte, preza justamente o bom senso, o gosto, um certo comedimento - embora, com a exposição característica das redes sociais, a discrição vá perdendo terreno -, valores que, nesse universo, são varridos do mapa. $\mathrm{O}$ que se encontra no cosplay não é o espalhafato, um exibicionismo à toa, mesmo porque os cosplayers são anônimos e assim continuarão. Logo, não se trata de conquistar quinze minutos de fama, mas de ser reconhecido plenamente como aquele personagem, em carne e osso. A experiência não consiste em ver alguém fantasiado, mas em ver e aquiescer que ali está, de fato, o Capitão América, o Darth Vader, a Tempestade ou a Mulher-Maravilha. Os cosplayers, assim, tornam-se os heróis de seus próprios eus; por isso, não há vergonha, não há recato - pelo contrário, a tônica é a euforia em se integrar àquele movimento. $\mathrm{O}$ pacto implícito entre cosplayers e público parece neutralizar um possível embaraço causado pelo inusitado da situação; o incômodo, nesse caso, se existente, é experimentado apenas pelos totalmente alheios àquele mundo e sua dinâmica.

Habitualmente, em eventos nos moldes da CCXP ocorre um concurso para se eleger o melhor cosplayer, com prêmios importantes. Também usuais são os desfiles, com massiva aprovação do público - em São Paulo, inclusive, as paradas eram um dos pontos altos da feira, um chamariz. Vale notar que os visitantes em geral, à paisana, sem realizar performances, também acabam se agregando ao momento ou colaborando com a questão da identificação, na medida em que tiram fotos, batem papo, trocam ideias com os cosplayers, como se estes fossem, deveras, seus personagens favoritos.

A identificação e o reconhecimento são assimilados por ambos os lados, tanto por aquele que se metamorfoseia em personagem, quanto pelo que entende o personagem como genuíno. Então, há um acordo, firmado de parte a parte, de que naquele instante ocorre uma mágica que transmuda o sujeito: quem está ali vestido não interpreta o personagem, e sim o é - e, do outro lado, a pessoa que aborda, tira fotos e conversa vem cultuar seu ídolo e ter contato com ele, seja um super-herói, super-heroína, monstro, vampiro, o objeto de sua adoração. $\mathrm{O}$ cosplayer, por conseguinte, foge à categoria "pessoa fantasiada" para encarnar a identidade, a personalidade e as ações de um Jedi, Harry Potter ou Malévola. O super-herói, aliás, assemelha-se, ele mesmo, a um cosplayer, na medida em que parte de um alter ego rumo a uma performance: assim, Batman a partir de Bruce Wayne, Super-Homem sobre Clark Kent, Flash e Barry Allen, Homem-Aranha e Peter Parker. O cosplay funciona, portanto, como rotação da realidade; os cosplayers 
rotacionam o entendimento da realidade porque aquilo que performam é real, experimentado e compartilhado. O essencial do indivíduo - se é que existe - amalgamase a outro.

Na CCXP, vi uma família inteira de cosplayers: o pai era o Indiana Jones, a mãe, Lara Croft e a criança era Dorothy, de $O$ mágico de $O z$. Nesse caso, percebemos que a prática do cosplay é estimulada dentro de núcleos importantes de convívio, sublinhando o aspecto de aproximação e agregação de iguais. Um dos fatores mais atraentes no evento foi observar pessoas diversas - algumas bastante excêntricas -, estranhas umas às outras, subitamente parando para tirar fotos e conversar longamente. Diferentes Chewbacca, diferentes Marty McFly, diferentes Wolverine - heróis da DC Comics se agrupavam para tirar fotos juntos, ou personagens da Marvel se reuniam para papear.

Também nesse contexto, verificamos a eleição, pelo público, de personagens, quase todos, de origem norte-americana, como a comprovar o peso do entretenimento dos EUA. Algumas das figuras mais queridas - à exceção de vários personagens japoneses muito populares, como Sakura Samurai, Pokémon, Son Goku de Dragon Ball e Mario Bros. - são majoritariamente derivadas da cultura pop americana. Assim, vemos, sobretudo, Mulher-Gato, Lanterna Verde, Thor, Bella Swan, de Crepúsculo, Branca de Neve, R2-D2, Baratheons, Targaryens, Lannisters e Starks, de Game of Thrones. A veneração a esses ícones gera debates entre os próprios aficionados do meio. Alguns assinalam a experiência geek como essencialmente americanizada e frisam a necessidade da missão de se aproveitar o buzz internacional para "abrasileirar" formas e temáticas; outros creem na existência de uma comunidade unida, espalhada pelo planeta, que compartilha temáticas e assim dialoga.

A polêmica está longe de terminar: em um painel de quadrinistas, alguns comentaram que sentiam forte cobrança para fazer narrativas "brasileiras", com temas e personagens próprios daqui. Na fala de Fábio Yabu, quadrinista e roteirista, participante da mesa "Mangá no Brasil": “[...] Vou fazer o quê? Saci samurai? Curupira assassino? Posso até fazer, mas não é o que me dá prazer, e não é muitas vezes o que o público quer. O barato de poder fazer uma história é poder fazer um robô, um androide assassino, samurai, é poder viajar." Para ele, os grandes temas da fantasia vinculam-se ao imaginário medieval, ao soturno - com zumbis, por exemplo - ou ao futurístico - os robôs. Os quadrinhos, parte importante da cultura geek, seriam baseados em histórias e enredos simples com roupagens e adornos fantásticos, em recriações da jornada do herói.

Com o tremendo impacto da fantasia na cultura, com o predomínio de narrativas fantásticas, cosplay, adoração a personagens extravagantes e/ou superpoderosos, esse universo sacramenta o triunfo dos "gordinhos" contra a cultura sarada, a vingança da leitura e do freak urbano contra o veraneio praiano, do aluno esforçado contra o brilhante desleixado, dos caretas e estranhos contra os populares e intelecos cool. Celebra-se aqui, principalmente, uma falta de limites prefixados e de censura - a vitória do que antes era taxado de brega, ridículo. A vitória do homem comum, com seus erros e acertos. 


\section{Referências}

ARCURI, Mariana Conde Moraes."Literatura em quadrinhos hoje”. Soletras, UERJ, n. 26, 2013.

BRANCO, Arnaldo; GUAZZELLI, Eloar; RAMOS, Graciliano. Vidas secas - graphic novel. Rio de Janeiro: Galera, 2015.

COSTA, Flávio Moreira da. "Rima e solução". In: MOON, Fábio; BÁ, Gabriel. O alienista. Rio de Janeiro: Agir, 2007.

DAHMER, André. "Entrevista”. Concedida em 11 ago. 2015.

GUAZZELLI, Eloar. Demônios. São Paulo: Peirópolis, 2010. . "Entrevista". Concedida em 14 jul. 2015.

O pagador de promessas. Rio de Janeiro: Agir, 2009.

HOMERO. Ilíada. Cotia: Ateliê Editorial/Unicamp, 2008.

JOY, Eileen A. etalii. Cultural Studies of the Modern Middle Ages. Macmillan, 2007. MALAPARTE, Curzio; GUAZZELLI, Eloar. Kaputt. São Paulo: WMF Martins Fontes, 2014.

MONTEIRO, Alzira Valéria. "Entrevista”. Concedida em 21 fev. 2011.

NASCIMENTO, Raquel. "Entrevista”. Concedida em fev. 2011.

OS INVISÍVEIS. Documentário de Bruno Correia, Bruno Fiuza, Rafael Barifouse. 2004.

ROSA, Guimarães; ROSA, Rodrigo; GUAZZELLI, Eloar. Grande sertão: veredas graphic novel. São Paulo: Biblioteca Azul, 2014.

SCLIAR, Moacyr. "Machado revisitado". In: MELADO, João Batista; SRBEK, Wellington. Memórias póstumas de Brás Cubas. Rio de Janeiro: Desiderata, 2010.

SIEBER, Allan. "Entrevista". Concedida em 08 jul. 2015.

SPACCA. Jubiabá. São Paulo: Quadrinhos na Cia., 2010.

THE MIDDLE Ages in the Modern World. University of Saint Andrews, 2013.

VASQUES, Edgar; BRAGA, Flávio. Triste fim de Policarpo Quaresma. Rio de Janeiro: Desiderata, 2010.

ZIMBRES, Fabio. "Entrevista”. Concedida em 15 jul. 2015. 